\title{
Kursbuch 185
}

\section{Fremd sein!}

Gregor Dotzauer Brief eines Lesers - Julia Kristeva Was ist ein Fremder? - Alfred Hackensberger Hidschra oder die Auswanderung in die Fremde - Naika Foroutan Wie lange bleibt man ein Fremder? • Bilal Tanweer Schwänzer - Mita Banerjee Der Fall des weißen Riesen - Florian Beaudenon Fremde Augenblicke • Alan Posener Der Jude als Fremder • Armin Nassehi Vertraute Fremde • Wolfgang Schmidbauer Fremd bleiben dürfen • Thomas Kron, Pascal Berger Moderner Terrorismus 
Kursbuch 185

Fremd sein 
Das Kursbuch erscheint viermal im Jahr.

Das Heft kostet einzeln $€ 19$,-

Das Jahresabo (4 Ausgaben) kostet €60,-

Im Internet: https://kursbuch.online

Sven Murmann Verlagsgesellschaft mbH

Miramar-Haus, Schopenstehl 15, 20095 Hamburg

Tel. 0 40/3980 83-0

V.i.S.d.P.: Peter Felixberger

(c) 2016 Sven Murmann Verlagsgesellschaft mbH, Hamburg

Alle Rechte für sämtliche Beiträge, auch der Übersetzung und der Wiedergabe durch Funk- und Fernsehsendungen und alle elektronischen Übermittlungen, vorbehalten.

ISBN 978-3-94651-400-8

ISSN 0023-5652

Herstellung und Gestaltung: Murmann Publishers GmbH, Hamburg

Druck: CPI books GmbH, Leck

Printed in Germany

Zuschriften bitte per Mail an: kursbuch@kursbuch.online

Abonnenten-Service: abonnements@kursbuch.online

Pressevertrieb: PressUp GmbH, Wandsbeker Allee 1, 22041 Hamburg. www.pressup.de 